to one which was shown by Dr. F. Parkes Weber ${ }^{1}$ before the Dermatological Section of the Royal Society of Medicine in 1909. In that case it turned out that the patient, a female, had many years ago been prescribed a pill containing a quarter of a grain of silver nitrate, and that she had taken this pill for about two years. The most careful inquiry, however, failed to elicit even the possibility that my patient had ever swallowed a silver compound. The alternative of ochronosis was effectually barred by the absence of any abnormal colouring material in the urine. All the cases which have up to the present time been published of that condition have been associated either with alkaptonuria due to the excretion of homogentisic acid, a congenital error of metabolism, or with melanuria due to the employment of carbolic acid, extending over many years, for the dressing of a chronic ulcer. ${ }^{2}$

Although there was no sign of serious visceral disease and both albumin and sugar were absent from the urine, there was a faint possibility that the case might be one of commencing hæmachromatosis, and at one time I thought that this was the most probable provisional diagnosis. We had, of course, considered the chance that the real cause of the curious staining of the skin was due to an alteration of the blood pigment, but this solution seemed to be negatived by the facts that the abnormal tint was so curiously localised, and, further, a spectroscopic examination of the blood when first made showed no abnormal band of absorption. My friend, Dr. Gordon R. Ward, however, persisted in the opinion he had formed from the appearance of the patient that the case was one of abnormal blood pigmentation, and I was very glad to give him an opportunity of examining the blood himself. Without any difficulty he succeeded in demonstrating in blood taken from the ear the characteristic absorption band of sulphæmoglobinæmia in the red end of the spectrum. He thus rescued the patient from the limbo of undiagnosed cases. A little later Mr. Mackenzie Wallis (demonstrator of chemical pathoIogy at St. Bartholomew's Hospital), who has for some time past been working on the subject of sulphæmoglobinæmia, also examined the blood spectroscopically. He first took a specimen from the finger; this was normal, and he was rather disappointed. I happened to be present myself, and suggested that he should try a specimen taken from the ear. In this specimen he had no difficulty in demonstrating the characteristic band.

The two facts that the peculiar colour of the skin is so definitely localised, and, further, that the spectroscopic characters of the blood vary according to the situation from which it is taken, combine to make this case, I believe, quite unique. Mr. Mackenzie Wallis also made some most interesting bacteriological investigations on this case, and succeeded in isolating an organism which in all probability is the cause of this condition. These investigations he will publish in a paper devoted to the subject of sulphæmoglobinæmia generally. He has been able to collect several other cases, all of the more usual type. For this reason I forbear from mentioning them further at the present moment or speculating on the probable etiology of the condition.

Additional note.-Since writing the above one or two other interesting points have come to light. In the first place, the depth of colour varies considerably from time to time, almost from minute to minute. For example, lately I have seen the tongue and lips quite blue, and then within a quarter of an hour they have regained the normal pink tint. Again, after having been out in the grounds for an hour or two on a rather chilly day the fingers, in addition to the bed of the nails, have been seen to be obviously affected. Lately, too, the pigmentation has shown a tendency to spread, and it seems probable that the curious localisation will disappear and that ultimately the discolouration will become obvious all over the body. Simultaneously with the deepening of the colour and its spread it is interesting to notice that the patient has complained of not feeling so well. Finally, I wish to express my indebtedness to Dr. W. J. Hadley, under whose care the patient was in the City of London Hospital for Diseases of the Chest, for giving me the opportunity of studying this interesting case.

Cavendish-square, $\mathrm{W}$.

1 Parkes Weber : A Case of Argrria, Proceedings of the Dermatological Section of the Royal Society of Medicine, 1910, p. 75.

2 Poulsen: Ochronosis bei Mengchen und Tidren, Beiträge Pathologischen Anatomie, vol. xlviii., pp. 346-498.

\section{A CASE OF MYXCEDEMA.}

BY R. S. NOVIS, M.R.C.S. ENG., L.R.C.P. LoNd., B.Sc.

Familiar as the classical symptoms of myxodema are, and universally recognised as the merits of the thyroid treatment are, I think it may be of use to put on record the notes of a typical case. The disease is not very common, and if the symptoms present themselves in any irregular or marked manner the diagnosis may not be immediate.

The patient, a man aged 60, first came under my notice in the early part of February last. Thyroid treatment was commenced on Feb. 17th. From the accompanying figures the remarkable alteration in his appearance is quite obvious.

When first consulted the patient had had symptoms extending over ten years. He had apparently followed his usual occupation (that of a blacksmith's labourer) without remission up to 12 months previous to my first seeing him. Since that time he would work, say, for a few weeks and then be compelled to cease, as he was quite unfit for anything that appertained to the least exertion. There was no. previous history of any illness of importance, and up to ten years ago he was always in good health. His symptoms seemed to have made very steady progress, until the time arrived when he was quite worn out, and he had certainly become so weak and depressed that life indeed was a burden. His memory had particularly failed him, likewise his sight and hearing. A marked feature was his great sensitiveness to cold. He would, in his own words, "feel cold with the heaviest clothes on a hot summer's day."

The face was broad and coarse in appearance. In the frontal and occipital regions there were marked swellings which did not "pit" on pressure. The eyelids were most markedly swollen, and under each eyelid could be seen what resembled a "bag" of fluid. These swellings obstructed the field of vision. The complexion was of the sallow type. A vascular blush, purplish-pink in colour, was present on each cheek-more marked on the left side. The lips were thick and swollen, the lower lip being everted. There had been loss of hair for some years, and the scalp at this time showed a very distinct absence of hair. There were sparse ones scattered here and there, mounted on small dark brown crusts. The loss of hair had also affected the eyebrows and eyelashes. The eyebrows were raised, and there was well-marked "wrinkling" of the forehead. The hands and feet were swollen-in fact, the whole body presented the same "bloated" appearance. The cedema of the feet was well marked in this case, which " pitted" on pressure, and which presented the white "glossy" appearance of remal disease. This cedema usually disappeared in the night and returned again during the day. The thyroid gland could not be felt, but much importance cannot be attached to this sign, as the thyroid gland in the normal male adult is difficult to palpate. The skin all over the body was dry and harsh. He had not perspired for years.

The patient complained of very severe headache, particularly in the frontal and occipital regions. He also suffered from severe lumbar pain. He had never vomited. There was frequency of micturition during the night (no enlarged prostate felt, no other symptoms of prostatic enlargement) the urine was pale, of specific gravity 1012 ; it was at first loaded with albumin, and there were a few tube casts. This albuminuria vanished shortly after the commencement of thyroid treatment and has never again been detected up to. the time of writing. Constipation was a very prominent symptom, which had appeared a year or so before treatment, and which entirely disappeared afterwards. The patient had also suffered from attacks of diarrhoea alternating with constipation. The heart and lungs were normal. The pulso was slow-60 per minute ; the temperature was subnormal$96 \cdot 2^{\circ} \mathrm{F}$.

The speech was of a deep, slow, sonorous, drawling, thick nature. The patient complained of deafness and dysphagia. There was no "ascites."

Thyroid treatment. - Weight of patient at commencement was 13 st. $7 \mathrm{lb}$. Messrs. Burroughs, Wellcome, and Co.'s tabloids were used. Feb. 17th: $1 \frac{1}{2} \mathrm{gr}$. administered fouv 
times a day after meals. 18th: Patient felt faint during the night. Was advised to rest for half an hour after taking each dose. Pulse 60 ; temperature $962^{\circ}$. Frontal headache and lumbar pain very marked. 20th: Pulse 64, fuller and stronger. 'Thyroid extract, 3 gr., as before. Cheeks not so full. Has perspired a little for the first time. 22nd: There are no untowarl symptoms. Patient says he feels better in himself. Speech is not so thick and words come nuch easier. Cheeks are becoming more sunken. Swelling over frontal region less; very much less at back of neck and over suprascapular regions. Temperature still subnormal, $96 \cdot 2^{\circ}$.

March 1st: Patient was now put on thyroid tabloids, 5 gr., twice daily. The bowels are acting naturally. The headache is much better; very little lumbar pain present. He says he feels as if he were losing flesh. He certainly looks thinner and altered in appearance. Pulse is more rapid and stronger. Temperature is normal for the first time. 16th: Patient put on tabloids, 5 gr., once a day. Improvement in general appearance is remarkable. He still

FIG. 1

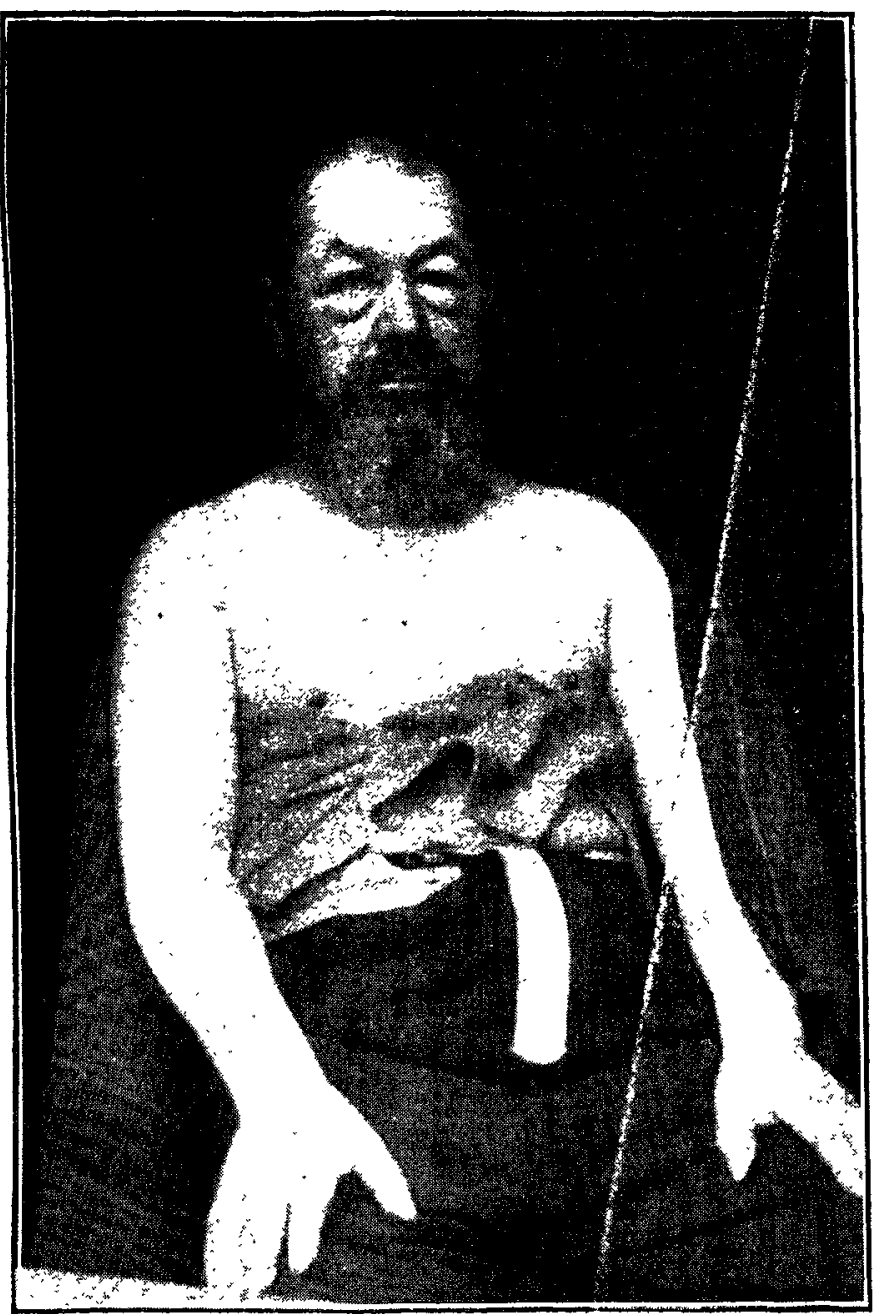

Reprorluction of photograph taken on Fob. 17th, 1912.

feels somewhat weak. Passes urine in normal quantity; specific gravity 1020. No albumin or sugar present. No headache, backache, or constipation. 19th : Improvement still continues. Speech is normal. He feels much stronger. Has taken a walk of a mile for the first time since treat ment was commenced. He did not feel in the least tired. He has also recovered his voice and was able to sing, not having been able to do this for many years. His deafness has completely gone.

April 1st: Patient still taking $5 \mathrm{gr}$. once a day. $\mathrm{He}$ feels much stronger. Pulse and temperature normal. 4th: "Peeling" is well marked on hands and feet, not present on the body. His weight is now 11 st. $11 \mathrm{lb}$. 11th: Is now taking $5 \mathrm{gr}$. every other day. He has continued to take this dose up to the present time (August, 1912)

The patient returned to his ordinary employment in the early part of June, 1912. I have kept him under observation. He says he feels strong and we!l, aud his never felt better in his life. His appearance has entirely changed. Friends who have not seen him for some years remark on the wonderful alteration of his appearance and often fail to recognise him. His hair las grown considerably, and is quite as thick, he says, as when he was 20 years of age. From its previous greyish appearance it has now returned to a clark-brown colour.

There are some interesting features in this case. In the first place the patient had been treated for some time for renal disease. The white, "glossy" œdema of ankles, the severe headache, frequency of micturition, swelling about eyelicls, low specific gravity of urine, presence of albumin and tube casts were highly suggestive of renal mischief. The diarrhœa alternating with constipation was also a prominent symptom in this case, and was at one time misleading, but the suggestion of malignant clisease was contradicted by a jrogressirely increasing body weight. Another point noticed in regard to the presence of albumin : during some days it was completely absent, or very nearly so. As the

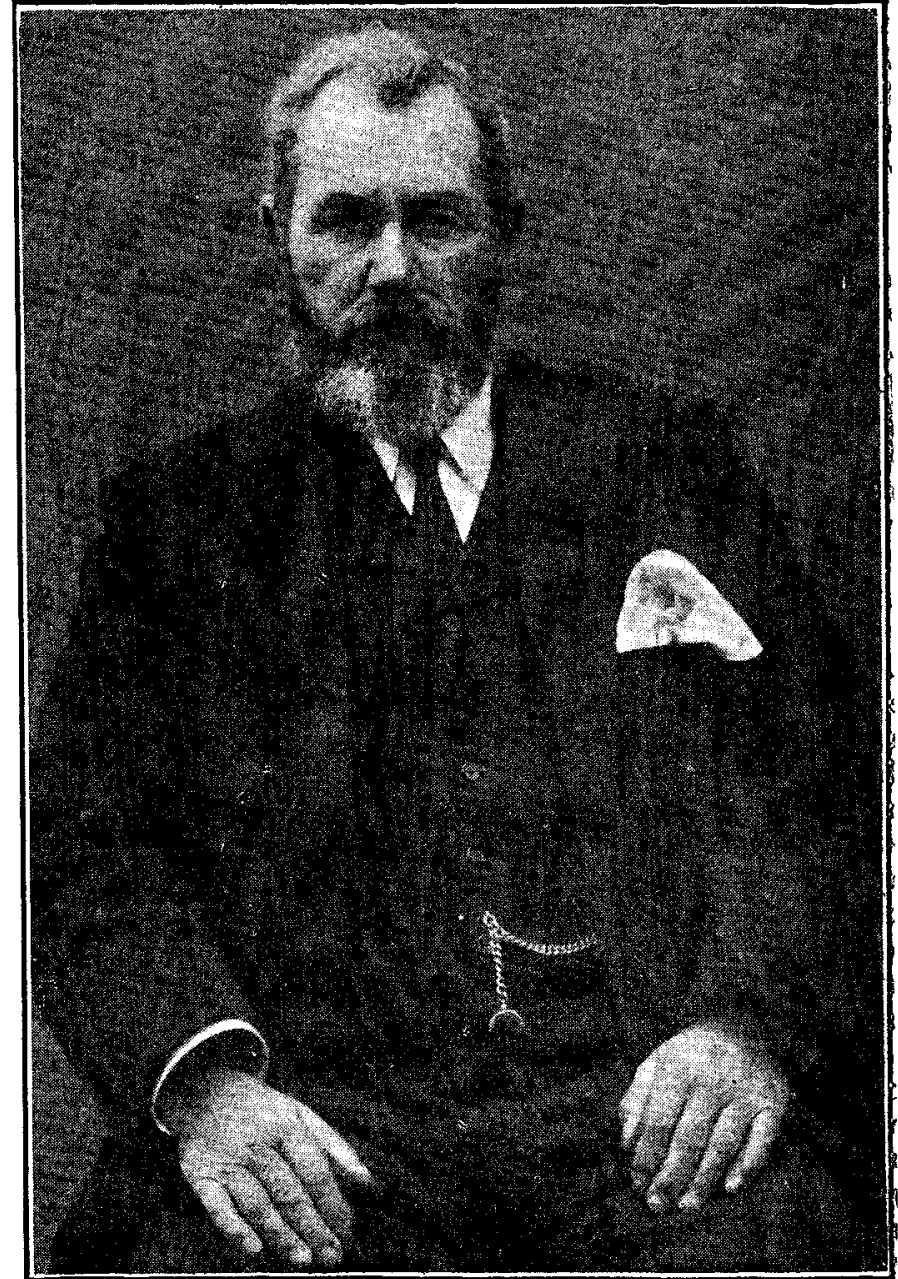

lieproduction of photograph taken on June $\varepsilon$ th, 1912.

thyroid treatment continued there was no further eridence of the presence of albumin or tube casts. The urine is now normal both as regards quantity and frequency. Another symptom noticed was the excessive irritability of the skin, particularly at night. This has now entirely disappeared.

A few words in conclusion in regard to treatment. There is nothing in the whole annals of medical knowledge which gives better prospects of a cure. In my opinion an important factor in the treatment of this disorder is to place the patient rapidly under the action of the gland, at the same time noticing any untoward symptoms which may arise as a result of large doses. MIoderate closes, as cletailed in my notes, gave the best and most rapid results in this case. When the benefit is pronounced it is advisable to reduce the dosage until the patient takes a small dose every alternate lay for practically the rest of his or her life. I also found that such tonics as iron, arsenic, and strychnine taken in combination were useful adjuncts in completing the cure.

Tuxfori, Newrark. 


\section{THE PRACTICAL USE OF VACCINE TREATMENT IN PULMONARY TUBERCULOSIS.}

By BERnARD hUdSON, M.D. CANTaB., M.R.C.P. LoNd

THEse few observations in vaccine-therapy, applicd in cases of pulmonary tuberculosis, are the outcome of three years' experience of this treatment in Davos-Platz, Switzerland, on about 400 cases.

In many cases of pulmonary tuberculosis the process is probably a double one-the tuberculous process proper and a superadded infection with some other organism or organisms. This is accounted for in the following manner The tuberculous focus being a part of lowered resistance, it is clear that it may verv easily become the seat of an infection with one of the numerous organisms normally present (and doing no harm in the normal individual) in the respiratory tract, nasal passages, mouth, pharynx, and trachea; in fact, I find it difficult to imagine a perfectly pure tuberculous infection of the lungs, one where there is no other inflammatory process at work. Moreover, there are certainly many cases where the main symptoms are due to the superadded infection.

Now, it is plain that any added non-tuberculous inflammatory process is an undesirable thing in that it acts as a continual source of irritation to the affected portion of lung, and does not give the tuberculosis a fair chance of healing. If, then, we can eliminate the added infection we remove this source of irritation and give the tuberculous process a better chance of coming to an end, and it is here that the value of vaccines comes in.

The cases may be divided under the following headings: 1. Cases where the process is one of pure tuberculosis. 2. Cases where there is some non-tuberculous inflammation in addition, but where the tuberculous process is so obviously by far the most important feature of the case that the mixed infection may be disregarded. 3. Slow, chronic cases, where there is a good deal of fibrosis going on, together with a certain amount of bronchitis and bronchiectasis in the affected portion of the lung. These cases are very liable to become infected with the organisms of eatarrh, and are suitable ones to try the effect of vaccines on. 4. Cases in which the main feature is not the tuberculosis, but in which chronic bronchitis dominates the scene, with a tendency towards periodical acute attacks. 5. Cases where there is a cavity formation. A cavity may become infected by some extraneous organism, learling to increased sputum, which is sometimes offensive. Also the temperature is raised, and there mav be the occurrence of hæmorrhages due to action of the organisms on partially thrombosed vessels.

In Cases 1 and 2 vaccine treatment will be useless, the process being one of tuberculosis essentially, but in the category of Cases 3,4 , and 5 , and, in fact, in any case where the physician suspects that some of the catarrh and general symptoms may be due to organisms other than the tubercle bacillus, the sputum should be cultivated and a vaccine prepared from the predominant organism. During the past three years I have prepared and administered vaccines to patients suffering from pulmonary tuberculosis in about 400 cases. Out of these there have been a certain number in which very marked beneficial results have ensued, the sputum quickly diminishing and in some cases disappearing, together with general all-round improvement. In other cases a certain amount of benefit has ensued, but not so marked as in the first group. But I am bound to admit that in by far the larger number of cases ( $70-80$ per cent.) no effect whatever has been produced, either bad or good. I may as well take the opportunity of remarking here that although in many cases no beneficial result has been obtained, I have never seen any case where permanent damage has resulted from the treatment, or, in fact, anything worse than a little temporary malaise, rise of temperature, and local soreness and tenderness at the site of injection.

The negative results so frequently obtained may be attributed to the following reasons : 1 . The case may not be one of mixed infection at all. 2. The difficulty, even in cases of undoubted mixed infection, of obtaining, among the varied flora which may often be grown from the sputum, the organism which is really causing the trouble. In all probability amongst the flora there are many organisms doing no harm at all, and exerting no pathological action, and a vaccine prepared from any of these will of course exert no action. If, on the other hand, one has the luck (and it really is, in my opinion, largely a matter of luck) to hit upon the organism which is really causing the trouble, then there follow the beneficial effects mentioned above. The extreme difficulty, then, of isolating the proper germ from the plate culture may, and probably does, account for the large percentage of non-successes which follow this treatment by vaccines prepared from the sputum. 3. The possibility of contamination of the sputum by the ordinary mouth organisms.

I have used vaccines prepared from a large variety of organisms, and the following is a list of those most commonly met with: micrococcus catarrhalis, dose up to 500 millions ; B. Friedländer, dose up to 500 millions; staphylococcus aurcus and albus, dose up to 500 millions; pneumococcus, dose up to 50 millions; streptococcus, dose up to 50 millions B. septus, dose up to 500 millions. The best effects seem to be obtained in cases where there is an infection with the diplococcus catarrhalis. The dosage should commence with 10 millions, and be gradually increased at intervals of four or five days up to 500 millions, the sequence being something like this (in millions): 10 (millions), 25, 50, 100, 200, $300,400,500$ (millions).

The B. Friedländer is always very useful to use, if present in the plates, the dose being about the same. (With the staphylococcus I have not had much success.) Pneumococcus should always be tried if found, and is often of great benefit.

Streptococcus may be frequently isolated, in cavity cases especially, and in this kind of case, with much offensive yellow sputum and high range of temperature, marked amelioration often ensues, the sputum diminishing and becoming less purulent, and the temperature abating a degree or two. As an example of the value of the streptococcus in a case where there is an infected cavity, I should like to cite the following case, which I observed during the winter of 1911-12.

Dec. 6th : Patient a male, aged 37. Extensive disease left lung, and extensive cavitation of upper lobe. Active disease arrested, patient very robust, and in good general health. Dec. 29th: Hrmorrhage, $\frac{1}{2}$ pint, and rise of temperature, ranging up to $100^{\circ}$ and $101^{\circ} \mathrm{F}$. The bleeding stopped in two days, but recurred again in 14 days' time; again ceased, but recurred in another 14 days, and so on until he had had eight hæmorrhages with 14 days' remission between each. During this time the temperature was rising to $100^{\circ}$ in the afternoon; the was offensive. After the sixth hæmorrhage I cultivated the sputum, isolated a short-chained streptococcus, and began injection. He had, it is true after this two more hæmorrhages, but the temperature gradually came down, and the sputum diminished and became much less purulent and more mucoid. The patient was up and about again on March 15th, and is now quite well-i.e., he has no signs of activity, and has regained
the condition of health which he had on Dec. 6th, 1911 .

I explain this case in the following manner. His carity became infected, and owing to ulceration through a vessel a hæmorrhage took place. This ceased and a clot formed. This clot was gradually digested by the organisms with which the cavity was infected, and finally was softened and gave way, thus giving rise to another hæmorrhage, and so on, the clot always taking about 14 days to become dis. integrated. On elimination of the mixed infection the whole process ceased. This case was a most instructive one for me, and I believe I have explained it correctly. In any case, the value of the streptococcic vaccine was quite indisputable and very striking.

The vaccine treatment may be used in conjunction with various kinds of tuberculin, and the rational method of treatment, in cases which are considered favourable, is, I think, to try to clear out any mixed infection that may be present with an appropriate vaccine, and then, having removed a source of irritation from the infected areas, to commence injections of tuberculin, of whatever variety may be considered suitable.

To resume, in certain cases of pulmonary tuberculosis, which must be selected according to the symptoms already mentioned, a course of vaccine treatment is certainly of great benefit. There is, however, always a large amount of uncertainty, owing to the difficulty of isolating the causal organism; but even if the vaccine does no good, it at any rate never seems to do any permanent damage, and therefore is always worth trying. The treatment may be used in conjunction with tuberculin, as already mentioned. It must be 